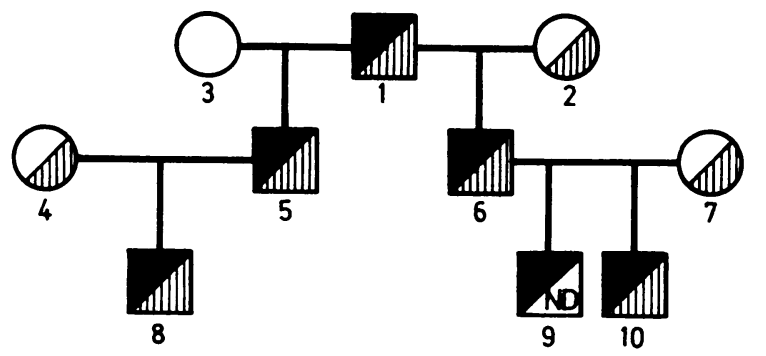

HLA haplotype : A2, B13, DR7

Impairment of leucocyte bcomotion

Family tree of subjects studied. All male members studied showed impaired leucocyte locomotion. Inheritance of single HLA haplotype indicated. (ND $=$ Not done.)

either number or morphology, and neither hypergammaglobulinaemia nor hypogammaglobulinaemia ${ }^{14-16}$ was present, suggesting that the defective locomotion was the only abnormality in a large range of immunological tests indicative of host defence. The defect of leucocyte locomotion and pyoderma were present in all male members of the family, while the women were free of symptoms. Chemoluminescence after ingestion of zymosan particles by leucocytes was normal in all members tested, so that an impairment of phagocytic and oxidative mechanisms appeared unlikely. ${ }^{11}$ The defect of leucocyte locomotion observed in the patients' mothers might have occurred as a secondary phenomenon due to repeated exposure to staphylococci present in their environment. ${ }^{17}$

Interestingly, all male members of the family had the same HLA haplotype. Hence the defect in leucocyte locomotion and the occurrence of symptoms might not only have been inherited in an $\mathrm{X}$ linked manner but might also have been linked to a gene within the inherited HLA haplotype. Further investiga- tions including more families with defects of leucocyte locomotion will be required to prove this and may shed new light on disturbances of leucocyte locomotion.

We are grateful to Dr W Mayr, Institute of Serology, University of Vienna, for HLA typing and to Drs H Ebner and D Kraft for measuring IgE concentrations.

\section{References}

1 Miller ME. Pathology of chemotaxis and random mobility. Semin Hematol 2 Quie PG, Cates RL. Clinical manifestations of disorders of neutrophil chemoQuie PG, Cates RL. Clinical manifestations of disorders of neutrophil chemo-
taxis. In: Gallin JI, Quie PG, eds. Leukocyte chemotaxis. New York: Raven

3 Clark RA. Disorders of granulocyte chemotaxis. In: Gallin JI, Quie PG, eds. Leukocyte chemotaxis. New York: Raven Press, 1978:329-56.

4 Miller ME, Oski FA, Harris MB. Lazy-leukocyte syndrome: a new disorder of neutrophil function. Lancet 1971 ; i :665-9.

Clark RA, Kimball HR. Defective granulocyte chemotaxis in the ChediakHigashi syndrome. F Clin Ivest $1971 ; 50: 2645-52$.
6 Hill HR, Ochs HD, Quie PG, Pabst HF, Klebanoff SJ, Wedgwood RJ. Defect in neutrophil granulocyte chemotaxis in Job's syndrome of recurrent "cold" staphylococcal abscesses. Lancet $1974 ;$ ii:617-9.

7 Hill HR, Quie PG. Raised serum IgE levels and defective neutrophil chemotaxis in three children with eczema and recurrent bacterial infections. Lancet $1974 ; \mathrm{i}: 183-7$.

8 Boyden S. The chemotactic effect of mixtures of antibody and antigen on polymorphonuclear leukocytes. F Exp Med 1962;115:453-66.

Frei PC, Baisero MH, Ochsner M. Chemotaxis of polymorphonuclears in vitro. f Immunol Methods 1974;6:357-86.

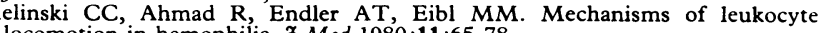

11 Grebner JV, Mills EL, Gray BH, Quie PG. Comparison of phagocytic and chemoluminescence response

12 Mayer MM. Experimental immunochemistry. 2nd ed. Springfield: CC Thomas, 1961:133-240.

3 Böyum A. Isolation of mononuclear cells and granulocytes from human blood: isolation of mononuclear cells by one centrifugation and of granulocytes by combining centrifugation and sedimentation at $1 \mathrm{~g}$. Scand $\mathcal{f}$ Clin Lab Invest $1968 ; 21$ (suppl 97):77-89.

14 Steerman RL, Snyderman R, Leiken SL, Colten HR. Intrinsic defect of the polymorphonuclear leukocyte resulting in impaired chemotaxis and phagocytosis. Clin Exp Immunol 1971;9:939-46.

JA, Dayton DH, eds. The phagocytic and humoral components. In: Bellanti JA, Dayton DH, eds.

16 Higgins GR, Swanson V, Yamazaki J. Granulocytasthenia. A unique leukocyte dysfunction associated with decreased resistance to infection. Clin Res 1970; 18:209.

17 Mowat AG, Baum J. Polymorphonuclear leukocyte chemotaxis in patients with bacterial infections. $\mathrm{Br}$ Med $\mathcal{F} 1971$;iii:617-9.

(Accepted 24 September 1984)

\title{
Efficacy of facemask resuscitation at birth
}

\author{
A D MILNER, H VYAS, I E HOPKIN
}

\section{Abstract}

The efficacy of facemask resuscitation was assessed by measuring the expiratory tidal volume during the first three inflations in nine babies with birth asphyxia and comparing the results with those obtained in a further nine babies resuscitated after endotracheal intubation. The facemask system was relatively inefficient, with tidal exchange less than one third of that seen after intubation and rarely sufficient to produce adequate alveolar ventilation. Successful resuscitation depended on stimulating the baby to make his own respiratory efforts.

\footnotetext{
Department of Child Health, City Hospital, Nottingham NG7 2UH A D MILNER, MD, FRCP, professor of paediatric respiratory medicine, department of neonatology

$\mathrm{H}$ VYAS, $\mathrm{MB}, \mathrm{MRCP}$, research fellow

I E HOPKIN, RSCN, research sister

Correspondence to: Professor A D Milner.
}

\section{Introduction}

Facemask resuscitation has been used for many years in the management of asphyxia at birth. It is easier and less invasive than intubation and so is often the first line of intervention by midwives. Although there have been no documented studies, it is generally accepted that most babies respond rapidly to facemask resuscitation and that it is a safe procedure. ${ }^{1}$ There have been worries that the positive pressure in the pharynx might lead to air passing down the oesophagus, producing gastric distension. This would tend to split the diaphragm and might impede tidal exchange. We, however, were unable to find any evidence that this occurred to any extent during standard facemask resuscitation in a recent study in which we measured both the facemask and oesophageal pressures during the procedure. ${ }^{2}$ As there have been no previous reports on the in vivo performance of these devices during resuscitation we considered it important to measure, in addition, both the inflation pressure and the resultant tidal exchange to assess whether these devices can maintain adequate ventilation during the first few minutes of life. We compared the results with 
data obtained from babies who had been intubated as part of the resuscitation procedure.

\section{Subjects and methods}

Subjects-Table I gives details of the babies in whom variables of facemask resuscitation were measured. These babies were matched with others who had been intubated at birth and on whom data had already been collected as part of an earlier study. ${ }^{3}$

Facemask resuscitation-Over 200 deliveries were attended. Babies who failed to start breathing within one minute were transferred to our own modified Vickers Resuscitaire. ${ }^{4}$ They were considered to be suffering from asphyxia if they had failed to start breathing by two minutes or their heart rate was below 80 beats/minute before that time despite skin stimulation and oropharyngeal suction. A micropressure transducer (Galetech) mounted near the tip of a $6 \mathrm{fg}$ catheter was passed transnasally in these babies so that the transducer lay in the lower third of the oesophagus. A Laerdal bag was used for all the facemask resuscitations. This has a pressure limiting blow off valve set at approximately $2.94 \mathrm{kPa}\left(30 \mathrm{~cm} \mathrm{H}_{2} \mathrm{O}\right)$. The standard facemask was replaced by an Ambu facemask in an attempt to achieve a better seal. ${ }^{2}$ Pressure within the facemask was recorded by inserting a 21 gauge butterfly needle high up in the facemask and connecting this to a strain gauge pressure transducer (SE Laboratories 8.46). Tidal flow and integration volume were measured by inserting a type O Fleisch pneumotachograph between the facemask and the body of the Laerdal resuscitator. Oxygen was fed in to the reservoir bag at the rate of $31 /$ minute, producing an oxygen concentration of up to $65 \%$ over the baby's face. The reservoir bag was squeezed 30-40 times a minute, each inflation lasting for up to half a second. After at least five inflations the blow off valve was obstructed to produce higher inflation pressures. Normal resuscitation was continued until the baby's own respiratory efforts were adequate. The signals from the transducers of oesophageal pressure and inflation pressure, flow, anc' volume were stored on magnetic tape and also displayed continuously on a four channel oscilloscope. The signals were subsequently fed on to ultraviolet sensitive paper for manual calculation. The oesophageal pressure and inflation pressure transducers were calibrated against a water column and the pneumotachograph against a rotameter and syringe.

Endotracheal intubation-The babies studied after intubation fulfilled the same criteria for asphyxiation. The monitoring equipment was identical except that the pneumotachograph was sited in the $T$ piece leading to the endotracheal tube and the inflation pressure measured at a port close to the insertion into the endotracheal tube.
Inflation was achieved by occluding the open port of the $T$ piece with a finger. The pressure was limited by a spring loaded valve. Further details have been given elsewhere. ${ }^{3}$ For the first inflation a pressure of approximately $2.94 \mathrm{kPa}\left(30 \mathrm{~cm} \mathrm{H}_{2} \mathrm{O}\right)$ was maintained for between one and five seconds; subsequently the inflation was maintained for one second, allowing a further second for expiration to occur.

\section{Results}

Despite the use of the Ambu facemask we could not achieve a total seal at the child's face. This had the advantage that the gaseous contents of the facemask were flushed at each inspiration, eliminating any additional dead space but meant that we could only analyse the expiratory tidal volume-that is, the volume coming out of the lungs as the inflation pressure fell. We found that, although the initial inflation pressures during the first three inflations were very similar using the two methods of resuscitation, the expiratory volumes during facemask resuscitation were less than a third of those achieved after intubation (table II). If adequate ventilation is defined as twice the anatomical dead space, assuming this to be $2 \cdot 2 \mathrm{ml} / \mathrm{kg}$ body weight, none of the initial three inflations on facemask resuscitation fulfilled these criteria but 10 inflations in five of the nine intubated babies exceeded this level. A Head's paradoxical reflex (inspiratory effort on behalf of the baby in response to the inflation) was seen on four occasions during facemask resuscitation and three occasions during endotracheal intubation.

The trace was also examined for the last three passive inflationsthat is, inflation not associated with any respiratory efforts on the part of the baby. This information was not obtained on one baby in each group, both of whom breathed with each inflation throughout the later part of the resuscitation. In a further two babies, one from each group, data could only be obtained on single breaths. Despite the inflation pressure rising in the babies undergoing facemask resuscitation to a mean $4 \mathrm{kPa}\left(40.8 \mathrm{~cm} \mathrm{H}_{2} \mathrm{O}\right)$ the mean tidal exchange was only $13.5 \mathrm{ml}$ compared with $22.0 \mathrm{ml}$ in the intubated babies. In these passive inflations only five of the eight babies achieved ventilatory exchange equivalent to twice the anatomical dead space compared with seven out of eight of the intubated babies. The mean interval between starting resuscitation and the first spontaneous breath leading to tidal exchange was $7.8 \mathrm{~s}$ during facemask resuscitation compared with $21.3 \mathrm{~s}$ after intubation. Spontaneous respiration started $60.8 \mathrm{~s}$ after the onset of intubation in the group to receive this treatment compared with $79.4 \mathrm{~s}$ after the start of facemask resuscitation. These differences did not reach significance (Student's $t$ test).

TABLE I-Clinical details of babies treated at birth for asphyxia by facemask resuscitation or endotracheal intubation

\begin{tabular}{|c|c|c|c|c|c|}
\hline \multirow{2}{*}{ Method of resuscitation } & \multirow{2}{*}{ No of boys } & \multirow{2}{*}{ Mean (range) gestation (weeks) } & \multirow{2}{*}{ Mean (range) birth weight (g) } & \multicolumn{2}{|l|}{ Delivery } \\
\hline & & & & Mode & No \\
\hline Facemask resuscitation $(n=9)$ & 7 & $38 \cdot 8(37-40)$ & $3260(1960-4740)$ & $\left\{\begin{array}{l}\text { Normal spontaneous delivery } \\
\text { Caesarean section } \\
\text { Ventouse } \\
\text { Breech }\end{array}\right.$ & $\begin{array}{l}5 \\
1 \\
2 \\
1\end{array}$ \\
\hline Endotracheal intubation $(n=9)$ & 5 & $38 \cdot 3(35-41)$ & $2830(1940-3690)$ & $\left\{\begin{array}{l}\text { Normal spontaneous delivery } \\
\text { Caesarean section } \\
\text { Ventouse } \\
\text { Breech } \\
\text { Keilland's forceps }\end{array}\right.$ & $\begin{array}{l}2 \\
2 \\
1 \\
3 \\
1\end{array}$ \\
\hline
\end{tabular}

TABLE II-Mean (range) inflation pressures and expiratory tidal exchanges during resuscitation. Data are on first three breaths and mean of last three passive inflations

\begin{tabular}{|c|c|c|c|c|c|c|c|c|}
\hline \multirow[b]{2}{*}{$\begin{array}{l}\text { Method of } \\
\text { resuscitation }\end{array}$} & \multicolumn{2}{|c|}{ First breath } & \multicolumn{2}{|c|}{ Second breath } & \multicolumn{2}{|c|}{ Third breath } & \multicolumn{2}{|c|}{ Last three passive inflations } \\
\hline & $\begin{array}{l}\text { Inflation } \\
\text { pressure } \\
(\mathrm{kPa})\end{array}$ & $\begin{array}{c}\text { Expiratory } \\
\text { tidal } \\
\text { exchange } \\
(\mathrm{ml})\end{array}$ & $\begin{array}{l}\text { Inflation } \\
\text { pressure } \\
(\mathrm{kPa})\end{array}$ & $\begin{array}{c}\text { Expiratory } \\
\text { tidal } \\
\text { pressure } \\
(\mathrm{ml})\end{array}$ & $\begin{array}{c}\text { Inflation } \\
\text { pressure } \\
\quad(\mathrm{kPa})\end{array}$ & $\begin{array}{c}\text { Expiratory } \\
\text { tidal } \\
\text { exchange } \\
(\mathrm{ml})\end{array}$ & $\begin{array}{l}\text { Inflation } \\
\text { pressure } \\
(\mathrm{kPa})\end{array}$ & $\begin{array}{c}\text { Expiratory } \\
\text { tidal } \\
\text { exchange } \\
(\mathrm{ml})\end{array}$ \\
\hline Facemask resuscitation & $\begin{array}{c}3 \cdot 08 \\
(2 \cdot 37-3 \cdot 58)\end{array}$ & $\begin{array}{c}3 \cdot 0 \\
(0-11 \cdot 1)\end{array}$ & $\begin{array}{c}3 \cdot 13 \\
(2 \cdot 39-3 \cdot 58)\end{array}$ & $\begin{array}{c}4 \cdot 7 \\
(0 \cdot 8-21 \cdot 8)\end{array}$ & $\begin{array}{c}3 \cdot 22 \\
(2 \cdot 72-3 \cdot 56)\end{array}$ & $\begin{array}{c}3 \cdot 9 \\
(1 \cdot 7-10 \cdot 6)\end{array}$ & $\begin{array}{c}4 \\
(2 \cdot 69-6 \cdot 07)\end{array}$ & $\begin{array}{c}13 \cdot 5 \\
(5 \cdot 6-20 \cdot 9)\end{array}$ \\
\hline Intubation & $\begin{array}{c}2 \cdot 76 \\
(2 \cdot 6-3 \cdot 26)\end{array}$ & $\begin{array}{c}14 \cdot 3 \\
(3 \cdot 3-43 \cdot 7)\end{array}$ & $\begin{array}{c}2 \cdot 91 \\
(2 \cdot 28-3 \cdot 26)\end{array}$ & $\begin{array}{c}10 \cdot 5 \\
(0-2 \cdot 9 \cdot 8)\end{array}$ & $\begin{array}{c}2 \cdot 71 \\
(2 \cdot 13-3 \cdot 26)\end{array}$ & $\begin{array}{c}17 \cdot 0 \\
(1 \cdot 8-53 \cdot 0)\end{array}$ & $\begin{array}{c}2 \cdot 45 \\
(1 \cdot 71-3 \cdot 23)\end{array}$ & $\begin{array}{c}22 \cdot 0 \\
(5 \cdot 6-33 \cdot 0)\end{array}$ \\
\hline p values* & NS & $<0.05$ & NS & NS & $<0.02$ & $<0.05$ & $<0.01$ & $<0.05$ \\
\hline
\end{tabular}




\section{Discussion}

A weakness of this study was that we were only able to measure the air leaving the lungs due to leaking around the facemask. Although data from our previous study makes it seem unlikely, ${ }^{4}$ some air may have remained in the lungs during the first three breaths and thus we may have underestimated the true tidal exchange. Nevertheless, we consider that the data in this paper indicate that facemask resuscitation rarely provides adequate gaseous exchange on its own. Despite this all the babies studied responded satisfactorily and were breathing within four minutes. During this period adequate tidal exchange appeared to be almost totally due to Head's paradoxical reflexes - that is, the inflation pressure inducing the baby to make inspiratory efforts. This almost always produced tidal exchange considerably in excess of twice the anatomical dead space. The time to the first effective respiratory effort tended to be earlier with facemask resuscitation, suggesting that the process of intubation might delay the onset of respiratory efforts. The time required for resuscitation was overall rather longer with facemask resuscitation, but this was almost entirely due to results from a single baby. The poor ventilatory response to the facemask system appeared to be due to the long time constant of the fluid filled lung, so that the relatively short period of inflation of the Laerdal bag was far too short to overcome the highly viscous forces. ${ }^{3}$ We suspect that increased ventilatory exchange could be achieved by modifying the blow off valve or by using a larger inflation reservoir. This might, however, lead to more air entering the oesophagus and distending the stomach. Our conclusion is that facemask resuscitation is effective if, as often happens, it stimulates reflex inspiratory efforts (Head's reflex). If this response does not occur endotracheal intubation is necessary to produce adequate exchange.

We thank the Medical Research Council for financial support and the midwives and obstetricians of the City Hospital, Nottingham, for their cooperation and encouragement.

\section{References}

1 American Heart Association. Basic life support in infants and children. $7 A M A$ $1980 ; 244: 472-8$.

Vyas $\mathrm{H}$, Milner AD, Hopkin IE. Facemask resuscitation: does it lead to gastric distension? Arch Dis Child 1983;58:373-5.

Vyas $\mathrm{H}$, Milner AD, Hopkin IE. Physiological responses to prolonged and slow rise inflation. F Pediatr 1981;99:635.

4 Vyas $\mathrm{H}$, Milner $\mathrm{AD}$, Hopkin IE. Intrathoracic pressure and volume changes during the spontaneous onset of respiration in babies born by caesarian section and by vaginal deliveries. $\mathcal{F}$ Pediatr $1981 ; 99: 787-91$.

(Accepted 12 September 1984)

\title{
Cutaneous insulin allergy responsive to oral desensitisation and aspirin
}

\author{
I M HOLDAWAY, J D WILSON
}

\begin{abstract}
A diabetic man with no previous history of allergy began to suffer itchy, painful swelling at the sites of injection after three months' treatment with bovine insulin. Insulin specific IgE concentrations $(1 \cdot 2-2.0 \mathrm{U} / \mathrm{ml})$ were higher than in non-allergic diabetics (mean 0.4 (SD 0.06) $\mathrm{U} / \mathrm{ml}$ ) but lower than in most other patients allergic to insulin (1.0-19.0 $\mathrm{U} / \mathrm{ml})$. Standard approaches failed to overcome the allergic reaction, and four separate attempts at desensitisation were unsuccessful.

The patient was then given oral insulin $800 \mathrm{U}$ thrice daily together with enteric coated aspirin $1300 \mathrm{mg}$ thrice daily for one week, and subsequent desensitisation with neutral insulin injection was carried out successfully. On stopping the aspirin the original reactions returned, and aspirin was therefore reinstituted as a permanent part of treatment.
\end{abstract}

Whatever the mechanism in this patient, oral desensitisation and aspirin provided a simple method for treating a difficult condition.

\footnotetext{
Departments of Endocrinology and Immunology, Auckland Hospital and Auckland University School of Medicine, Auckland, New Zealand

I M HOLDAWAY, MD, FRACP, endocrinologist and associate professor of medicine

J D WILSON, MD, FRACP, immunologist and associate professor of medicine

Correspondence to: Dr I M Holdaway, Associate Professor of Medicine, Auckland Hospital, Auckland 1, New Zealand.
}

\section{Introduction}

Allergy to insulin may be local or systemic ${ }^{1}$ and is usually due to antigenicity of non-human insulin, additives, or contaminants. We describe a patient with localised insulin allergy resistant to standard desensitisation regimens who responded to oral desensitisation together with administration of a non-steroidal anti-inflammatory agent.

\section{Case history}

A 37 year old diabetic man presenting with ketosis and weight loss developed cutaneous allergy after three months' treatment with bovine insulin. Coin sized raised, red, itchy swellings developed within 15 minutes of injection, with some larger swellings associated with deep throbbing pain. Often a typical reaction would be associated with itchiness, swelling, and redness at the site of previous injections. The reactions corresponded to an "immediate" type of cutaneous allergy. There was no personal or family history of allergy.

Insulin specific IgE antibodies were measured by adsorption to an insulin-Sepharose column and quantified by reaction with iodine- 125 labelled antihuman IgE. ${ }^{2}$ Mean insulin specific IgE concentrations in the patient ranged from 1.2 to $2.0 \mathrm{U} / \mathrm{ml}$ compared with 1.0 to $19.0 \mathrm{U} / \mathrm{ml}$ in other patients with insulin allergy, $0.6(\mathrm{SD} 0.1) \mathrm{U} / \mathrm{ml}$ in non-diabetics, and $0.4(\mathrm{SD} 0.06) \mathrm{U} / \mathrm{ml}$ in non-allergic diabetics. ${ }^{2}$

Four different approaches were used in an effort to overcome the allergic reaction-namely, reduction in antigenicity of the injected material; desensitisation to reduce allergic sensitivity; use of antagonists to the mediators of the allergic reaction; and prevention of synthesis of allergy mediators. Insulin was withdrawn and the patient treated with restricted diet and oral hypoglycaemic agents during attempts at desensitisation. Bovine or porcine insulin from various manufacturers; highly purified monocomponent porcine, bovine, and human insulin (Novo Industries); desphe insulin (Hoescht); and zinc free sodium insulin (Eli Lilly) all caused brisk 